\title{
Juventude: Idades da Vida e Gerações*
}

\section{Gérard Mauger}

Diretor emérito do Centre National de la Recherche Scientifique (CNRS) e pesquisador do Centre de Sociologie et de Science Politique (CESSP), CNRS-PARIS I-EHESS.

E-mail: gerard.mauger@cse.cnrs.fr

1 eria necessária uma revisão da história das ideias cuja hipótese

$\mathcal{O}$ é que os textos são lidos e, uma vez lidos, estão compreendidos etc. Em geral, o que circula são os títulos", escrevia Pierre Bourdieu a respeito de Michel Foucault (Bourdieu, 1996:13-18). A observação tem a ver com o título que ele dera a uma antiga entrevista com Anne-Marie Métailié: "Juventude é apenas uma palavra" (Bourdieu, 1978:520-530). A principal intenção desse título não era dissuadir os "especialistas em juventude" de perseverar em sua tarefa, mas de chamar-lhes a atenção sobre a diversidade de condições que leva a mascarar, quando reagrupadas sob um mesmo nome, a noção de "juventude": "é um formidável abuso de linguagem, explicava Bourdieu, subsumir sob o mesmo conceito universos sociais que praticamente nada têm em comum", e acrescentava que "é preciso ao menos analisar as diferenças entre as juventudes, ou para ser breve, entre as duas juventudes": de um lado, "os herdeiros", do outro, "os jovens sem futuro".

\footnotetext{
* Este artigo foi, originariamente, apresentado no seminário "Juventude, Desigualdades e o Futuro do Rio de Janeiro", realizado na Casa de Rui Barbosa, em junho de 2011, como parte das atividades do Programa de Apoio a Núcleos de Excelência (Pronex), sediado no Instituto de Estudos Sociais e Políticos (IESP), da Universidade do Estado do Rio de Janeiro (UERJ). [A tradução do original em francês, "Jeunesse: âges de la vie et générations" é de Estela Abreu].
}

DADOS - Revista de Ciências Sociais, Rio de Janeiro, vol. 56, no-1, 2013, pp. 169 a 183. 
Por mais evidente que fosse a constatação, o lembrete não era inútil e continua a valer hoje, época em que se propagam as teorias antagônicas mas complementares da "medianização" e da "individualização". De fato, se esse abuso de linguagem se perpetua, a despeito dos desmentidos da objetivação estatística e das evidências da sociologia espontânea, é porque as diferentes categorias de "profissionais em juventude" têm "interesse pela juventude" (isto é, pela perpetuação da crença na pertinência do seu objeto de estudo ou do seu campo de intervenção); e também por causa das ilusões mantidas por esse tipo de noção: ao apresentar uma igualdade de princípio contra uma desigualdade de fato, fica garantida a adesão de todos que, socialmente dominados, têm aparente interesse por esse rótulo unificador e pela negação da desigualdade social que o acompanha.

Mas essa é uma leitura redutora. Para mostrar o amálgama progressivo das oposições entre "as duas juventudes", Bourdieu esboça, na mesma entrevista, a construção de uma definição social da juventude pensada não como "uma unidade social [...], um grupo constituído, dotado de interesses comuns [...], com referência a uma idade definida biologicamente", mas como uma sequência de trajetória biográfica: uma "idade da vida", um estado intermediário, "meio criança, meio adulto", "nem criança, nem adulto". Por outro lado, ele trata, a esse respeito, da questão dos conflitos de gerações, lembrando que "muitos conflitos de geração são conflitos entre sistemas de aspirações constituídos em diferentes idades" e que eles se originam também nas oposições entre "detentores" (dos patrimônios e das posições) e "pretendentes". "Idade da vida" (cf. Mauger, 1995; 2010b) e "geração" (cf. Mauger, 2009): são as duas tentativas de "construção de objeto" ligadas à noção de "juventude". Aqui tentaremos clarificar essas duas perspectivas: "Às vezes é preciso retirar da linguagem uma expressão e mandar limpá-la - para, depois, pô-la de novo em circulação", dizia Wittgenstein (1990).

\section{IDADES DA VIDA, GERAÇÕES FAMILIARES E GERAÇÕES SOCIAIS}

De fato, o levantamento dos usos comuns das noções de idade e de geração mostra três noções distintas, mas ligadas: a de "idade da vida", a de "geração familiar" e a de "geração social". Começo evocando rapidamente as relações entre essas três noções. 
Inscritas em uma perspectiva diacrônica, todas estão ligadas a um trabalho de periodização: a noção de "idade de vida" está associada às tentativas de periodização do curso de uma trajetória biográfica; a de "geração familiar", à periodização das linhagens familiares; e a de "geração social", às tentativas de periodização do curso da história de uma sociedade.

"Efeito de geração" (ou de bando), "efeito de idade" (ou de posição no ciclo de vida) e "efeito de momento" (ou de período) aparecem inextricavelmente ligados: o "efeito de geração" designa as marcas deixadas pela história nos membros de uma mesma geração, o "efeito de idade" designa os efeitos associados a uma posição no ciclo de vida e o "efeito de momento" designa as incidências de uma conjuntura ou de um acontecimento determinado sobre todos aqueles que lhe são confrontados (cf. Kessler e Masson, 1985:285-321).

Inscritas na contiguidade das características universais da existência corporal, essas noções lembram a necessidade, para toda a sociedade, da "reprodução simples" de seus próprios fundamentos: reprodução biológica do grupo e produção da quantidade de bens necessários à sua subsistência e, indissociavelmente, reprodução das estruturas sociais em que elas ocorrem.

Mais exatamente, "idades da vida", "gerações familiares" e "gerações sociais" dependem do "modo de reprodução". A "reprodução" (que não exclui a "mobilidade") designa a transmissão intergeracional das diferentes espécies de capitais (capital econômico, capital cultural, capital social, capital simbólico) e das disposições correspondentes e, como decorrência, a reprodução das hierarquias e da ordem social. Uma "geração social" é o produto dos seus anos de formação, isto é, o produto de um dos quadros de "socialização básica" (família, escola, trabalho etc.) que define o "modo de ser de uma geração". A um determinado "modo de ser de uma geração", corresponde um "padrão por idade" (cf. Percheron e Rémond, 1991) que delimita os limiares de "etapas de vida" e as "faixas de idade de vida" dentro das trajetórias biográficas. Seja qual for o "modo de ser de uma geração", a família ocupa lugar central na reprodução biológica e social, isto é, na transmissão das diferentes espécies de capital e na interiorização das disposições características de um "habitus de classe": a herança sob todas as suas formas sustenta as relações entre "gerações familiares" e contribui para a periodização das trajetórias biográficas. 


\section{Modo de Geração e Gerações}

É possível definir um "modo de reprodução" (Bourdieu, 1989:373-427) pelo sistema de "estratégias de reprodução" adaptado às particularidades do patrimônio familiar que se trata de reproduzir: estratégias de fecundidade, estratégias de sucessão, estratégias educativas, estratégias matrimoniais etc. Ao "modo de reprodução familiar", associado à propriedade familiar de empresas agrícolas, industriais ou comerciais que se quer transmitir (quase sempre de pai para filho), opõe-se o "modo de reprodução de âmbito escolar", ligado às grandes empresas burocráticas cujo capital está dispersado e em que o título escolar torna-se um verdadeiro "direito de entrada". A diferença fundamental entre os dois modos de reprodução reside na lógica propriamente estatística do modo de reprodução de âmbito escolar (existem "fracassados" e "miraculados" do sistema escolar). Esses dois modos de reprodução que opõem esquematicamente o recurso à família e o recurso à escola nos mecanismos de transmissão são hoje coexistentes.

Seja qual for o "modo de reprodução" - modo de reprodução familiar ou modo de reprodução de âmbito escolar -, a instituição familiar tem papel central não apenas na transmissão do capital econômico, mas também na transmissão do capital cultural (decisivo no êxito como no fracasso escolar, visto que a obtenção de títulos escolares pode ser descrita esquematicamente como operação de conversão do "capital cultural incorporado" em "capital cultural institucionalizado") (Bourdieu, 1979:3-6). Assim, é possível estudar as relações entre "gerações familiares" sob o ângulo da economia das trocas entre gerações e destacar a elevação das trajetórias biográficas que essas relações induzem.

De modo geral, toda mudança no modo de reprodução, isto é, todo novo estado dos mecanismos institucionalizados que funcionam como instrumentos de reprodução ou, em outros termos, toda transformação do modo de geração das gerações sucessivas dá origem a crises de reprodução e à aparição de "gerações sociais" distintas. Mas essas transformações (como, por exemplo, as mudanças no direito de sucessão ou a democratização do sistema escolar) não têm a mesma incidência sobre as diferentes "regiões" do espaço social, de forma que é preciso tentar cercar os efeitos socialmente diferenciados das transformações do "modo de reprodução". O que supõe estabelecer um mapa do espaço social em uma ou outra escala: macrossociológica (na escala 
das classes sociais ou dos campos) ou microssociológica (na escala da família ou do indivíduo). Trata-se então de identificar, na escala de uma linhagem familiar, na escala de um campo ou na escala de uma classe social (como na de uma profissão), as mudanças ocorridas na definição das posições a ocupar ou nas maneiras institucionalizadas de a elas aceder. As diferenças entre gerações assim delimitadas são ainda maiores quando essas mudanças são mais importantes, e a probabilidade para essas gerações de existir em estado de "unidades de geração" (como dizia Mannheim, 2011) é tanto mais elevada quanto mais próximos os agentes reunidos estiverem no espaço social e se pertencerem a uma região do espaço social mais restrita, logo, mais homogênea.

a) $\mathrm{Na}$ escala de uma linhagem, as relações entre gerações variam em função da composição do patrimônio familiar a transmitir (de dominante econômica/de dominante cultural), do valor desse patrimônio, da aptidão do herdeiro para herdar a herança, mas também do estado da legislação sobre as heranças, possibilidades de reconversão dos filhos, do funcionamento do mercado matrimonial etc. Sem pretender que o conflito pai/filho seja inevitável, ocorre que as relações entre "pais detentores" e "filhos pretendentes" são variáveis: do conflito declarado até as sucessões sem contestação, passando pelas diferentes formas de negociação, de transações, de compromissos (Mannheim, 2011).

b) Na escala de um "campo" do espaço social, as flutuações do "direito de entrada" (revisado "na alta" ou na "baixa") permitem delimitar gerações que diferem por seu modo de geração. De tal modo que os conflitos recorrentes que as atravessam entre "detentores" (dos lugares e das responsabilidades) e "pretendentes" a esses mesmos lugares opõem de fato modos de geração diferentes sob a aparência de opor "jovens" (que os "velhos" veem como inexperientes) a "velhos" (que os "jovens" consideram arcaicos). Nessa luta entre detentores e pretendentes, os pretendentes tentam impor uma nova definição de "excelência" ligada ao seu próprio modo de geração.

c) Na escala de uma classe social, é possível observar, por exemplo, que, ao contrário das profissões liberais (e em particular dos médicos), que souberam manter a definição tradicional do cargo e das competências por ele exigidas, além de defender condições malthusianas de acesso ao cargo ("numerus clausus"), categorias como as dos executivos 
e engenheiros viram durante muito tempo antigos funcionários promovidos "por tempo de serviço" oporem-se aos novos que ingressam "por titulação". Cabe também destacar, no mundo operário, os conflitos de gerações associados às transformações do modo de geração do grupo operário, que opõem a "cultura de rebelião" da "geração proletarizada" dos anos 1970 ao "individualismo negativo" da "geração precária" dos anos 1990 (Mauger, 2010a:187-196).

d) Na escala de uma formação social, o "esquema do acontecimento fundador" pode explicar o aparecimento de "gerações sociais". Ele se baseia em uma dupla hipótese: por um lado, a da existência de ocorrências capazes de exercer efeitos duráveis sobre quem passou por essa experiência; por outro, a de efeitos diferenciais do acontecimento segundo a idade dos que passaram por isso ${ }^{1}$. É possível distinguir três categorias de "acontecimentos fundadores": as revoluções que redefinem mais ou menos radicalmente os modos de reprodução e os quadros de socialização; as guerras que suspendem mais ou menos duravelmente o curso das trajetórias biográficas dos combatentes; as crises políticas que abalam mais ou menos duravelmente a ordem social, sem que se possa objetivar com tanta facilidade mudanças de quadros de socialização ou inflexões do curso das trajetórias biográficas. Acontecimentos "traumáticos", acontecimentos "matriciais", são vistos como capazes de exercer efeitos bastante significativos e duráveis sobre quem os viveu para fazer nascer uma "geração social".

\section{A JUVENTUDE: VARIAÇÕES E INVARIANTES DA CONDIÇÃO JUVENIL}

A um modo de reprodução, definido por um estado das instituições de socialização, corresponde um "padrão por idade" cada vez mais exato e sistemático, isto é, um trabalho político de organização da massa dos súditos ou cidadãos em função de sua idade: ele marca com múltiplos limites o curso das existências individuais e organiza a estruturação, por idade, da população. Assim, toda tentativa de periodização de uma trajetória biográfica (ou de um feixe de trajetórias) deve levar em conta duas ordens de acontecimentos distintos, mas relativamente dependentes: "acontecimentos biográficos", que pontuam os diferentes percursos constitutivos de uma trajetória (cujas regularidades refletem um estado do "padrão das idades") e "acontecimentos históricos", que pontuam o devir das estruturas sociais e deixam marcas nas trajetórias individuais. 
Em uma fase historicamente estabilizada do modo de reprodução e abstraindo desses acontecimentos históricos, para definir sociologicamente a sequência de trajetória biográfica que designa a noção de "juventude", é preciso situar os "acontecimentos biográficos" marcantes dos diferentes percursos integrados em uma trajetória. Se nos detivermos nos percursos familiares, escolares e profissionais, é possível considerar que a juventude é a idade da vida em que se opera a dupla passagem da escola para a vida profissional e da família de origem para a família conjugal, a sequência de trajetória biográfica definida pelo duplo processo de acesso a uma posição estabilizada no mercado de trabalho e no mercado matrimonial.

Seja qual for o calendário, esse duplo processo de acesso a um "estado" profissional e conjugal considerado, ao menos provisoriamente, como definitivo, define uma condição, invariante estrutural própria do conjunto dos jovens (ou quase). As analogias de condição que essa identidade de posição implica no tempo biográfico dão origem a um conjunto de disposições genéricas próprias daqueles que partilham essa condição. Assim, a construção sociológica proposta permite explicar, a seu modo, atitudes, comportamentos partilhados - a "crise de identidade juvenil" - que a psicanálise, em seu registro, explica, ou que o senso comum atribui a "uma natureza jovem", e da dispersão social das trajetórias biográficas, que permite explicar a heterogeneidade objetiva e subjetiva "da juventude". Essa situação de dupla passagem que caracteriza a juventude pode ser descrita como um período de "acumulação primitiva", de "ausência de gravidade" e de "incoerências de status", de "indeterminação social", de "classificações" e de "cristalização dos habitus".

\section{A Idade da Acumulação Primitiva}

Aplicando-se a diferentes momentos do ciclo de vida e cronologicamente articuladas, as estratégias familiares de reprodução - estratégias de fecundidade (procurando reduzir o número de pretendentes ao patrimônio), estratégias de sucessão (procurando garantir a transmissão do patrimônio entre gerações familiares com o mínimo de perda), estratégias educativas, das quais as estratégias escolares são um caso particular (procurando produzir herdeiros dignos de receber a herança), estratégias propriamente econômicas (destinadas a garantir a reprodução ampliada do patrimônio econômico), estratégias de investimento social (destinadas à manutenção e à acumulação do capital so- 
cial), estratégias matrimoniais (garantindo a reprodução biológica da linhagem sem ameaçar sua reprodução social) - dependem do volume e da composição do patrimônio a transmitir.

A transmissão do capital econômico (sob suas diferentes formas: instrumentos de produção, bens imobiliários, valores mobiliários, liquidez etc.) entre gerações familiares se exerce por herança, doações e ajudas. Ela contribui de modo decisivo para reproduzir as desigualdades econômicas de geração em geração. De modo geral, todas as vezes que a família possui o controle total de um patrimônio formado por uma empresa agrícola, industrial ou comercial, as estratégias pelas quais ela procura garantir sua própria reprodução tendem a se subordinar às estratégias propriamente econômicas no intento de garantir a reprodução do capital econômico. O nível de renda é evidentemente discriminante nas ajudas monetárias, ocasionais ou regulares: elas ocorrem em diferentes momentos da vida dos filhos, quase sempre durante o período de estudos, depois, no momento em que se "instalam" e, a seguir, durante a busca do primeiro emprego estável.

A transmissão do capital cultural entre gerações familiares ajuda a explicar desvios constatados entre as probabilidades objetivas de êxito escolar segundo a origem social. A desigualdade no êxito escolar encontra seu princípio na distância desigual entre "a cultura" herdada da classe de origem e "a cultura escolar". Adquire-se o capital cultural, essencialmente, de modo dissimulado (inconsciente e invisível): em particular, pela aprendizagem "espontânea" da língua e dos usos familiares, pelo efeito educativo exercido pelo capital cultural objetivado e integrado ao ambiente familiar e por todas as formas de transmissão implícita. Em razão do alto grau de dissimulação de sua transmissão hereditária, ele é predisposto a funcionar como "capital simbólico", isto é, desconhecido e reconhecido, acumulando o prestígio da propriedade inata e o mérito da aquisição. Mas ele também é adquirido graças a estratégias educativas conscientemente empregadas e a um trabalho de inculcação explicitamente concebido como tal, mas quase sempre dissimulado.

\section{A Idade da Ausência de Gravidade}

A ausência de gravidade familiar caracteriza a sequência "juventude" na medida em que a libertação progressiva em relação à família de origem permite furtar-se, prática e subjetivamente, às obrigações que ela exige, sem com isso já se sujeitar às de uma nova família, ficando claro que as regalias às quais acedem progressivamente rapazes e moças são 
social e sexualmente diferenciadas e que as obrigações progressivas que se impõem, para eles e elas, como a passagem de um casal precário a um casal estável, de um casal estável a um casal "instalado", casado ou não, também o são. Essa sequência de trajetória biográfica também pode ser descrita como um estado de relativa "ausência de gravidade" econômica, por um lado, por causa da prolongada assistência econômica da família de origem que sustenta, no todo ou em parte, estudantes e jovens desempregados e que permanece por muito tempo um recurso possível (por exemplo, em caso de fracasso de uma experiência de coabitação juvenil), por outro, por causa da assistência econômica que recebem estudantes e jovens trabalhadores, ou ainda da ausênciaprovisória - da pressão econômica exercida pela instalação de uma nova unidade familiar estável, isto é, com filho(s). Assim, compreende-se que a juventude seja também "a idade dos compromissos" (com os riscos que eles comportam) e que, nas camadas populares sobretudo, a juventude também seja (ao menos para os homens) "o tempo da liberdade", provisoriamente isento das obrigações específicas que existem para pais e mães de famílias modestas: nesse mundo, mais que em qualquer outro, trata-se de "aproveitar a juventude" antes que se feche esse parêntese de relativa liberdade.

\section{A Idade das Incoerências de Status}

Se a revolta ou o desencanto habituais do jovem têm origem quase sempre no hiato entre o que ele espera e o que encontra ao ingressar no mercado de trabalho, podem também resultar da distância entre os atributos estatutários dessa sequência de trajetória biográfica, aquela condição "nem criança, nem adulto", definida por um conjunto particular e temporário de deveres, privilégios e interditos (cf. Chamboredon, 1985:13-28). Os privilégios se adquirem progressivamente e quase sempre depois de provas (quase todas hoje de tipo escolar), enquanto persistem interditos da infância. Ao inverso, surgem novos deveres enquanto desaparecem privilégios do tempo da infância. $\mathrm{O}$ conjunto desses atributos estatutários, que diferem de acordo com o sexo e a classe social, resulta em um status ambíguo que não pode ser definido em termos de privação e de dependência, nem em termos de privilégios e de independência: é a não concordância dos calendários de acesso à maturidade que constitui a regra; está muitas vezes na raiz da revolta ou do mal-estar próprios dessa sequência de trajetória biográfica. Mas a urgência de estabelecer-se, resultante nos anos 1960 da inevitável tensão familiar no momento da adolescência, perdeu força com o desenvolvimento da contracepção, da liberação do aborto e da aproxi- 
mação das atitudes de pais e jovens quanto à moral cotidiana e, especialmente, à moral sexual.

\section{A Idade da Indeterminação}

Como a situação de transição entre uma posição social inicial (definida pela da família de origem e por uma posição escolar) e uma posição futura (definida pela inserção profissional e pela aliança matrimonial "definitivas") já não pode ser definida pela posição de partida e também ainda não pela posição de chegada (que permanece mais ou menos virtual), a juventude é uma situação de indeterminação: indeterminação profissional e matrimonial variável de um polo ao outro do espaço social e que se reduz com o correr do tempo. Ela é mínima quando o futuro parece definido à saída do sistema escolar, ou seja, quando o volume e a composição dos recursos acumulados são tais que o leque das possibilidades profissionais e matrimoniais já se fechou bastante: ou porque a desclassificação e o mau casamento estão praticamente excluídos, ou porque a ascensão profissional e/ou o "bom casamento" parecem improváveis. Se a maioria dos jovens de meios populares (operários, empregados ou desempregados) não tem ilusão sobre o futuro de classe e vê de forma realista a sua situação, por sua vez, aqueles provenientes das classes dominantes também não tem outra possibilidade de futuro a não ser reproduzir sua posição de origem, e cultivam às vezes, ao inverso, uma visão indeterminada da sua situação presente: posição arrancada ao peso da família de origem como ao de um futuro, indefinidamente recuado, mas garantido.

Essa garantia (objetiva e subjetiva) pode então provocar o desapego ostentado, a ilusão, escolarmente encorajada, de poder fugir às leis da gravidade social, as representações de si como sujeitos singulares irredutíveis a qualquer determinação social (cf. Bourdieu, 1992). À liberdade provisória sem ilusão dos que já estão destinados às posições dominadas do espaço social, opõe-se a ilusão provisória de liberdade dos herdeiros. A indeterminação é a maior possível, ao inverso, em todas as situações em que a composição do patrimônio detido (e, em particular, a relação entre capital econômico e capital cultural) é equilibrada: situação indeterminada, a juventude determina então à indeterminação, à indecisão.

\section{A Idade das Classificações}

Provisoriamente indeterminada, inclassificável, a juventude é também a idade das classificações na medida em que pode ser descrita 
como a sequência de trajetória biográfica durante a qual novatos(as) / pretendentes chegam ao mercado de trabalho e ao mercado matrimonial e neles negociam posição profissional e aliança matrimonial. Classificações (as que eles fazem e as das quais são objeto) que dependem do volume e das diferentes espécies de capital (cultural, escolar, econômico, social, simbólico) detido, adquirido e (ou) herdado, atual e (ou) potencial. O estudo das relações entre classificações e autoclassificações (em particular profissionais), entre as posições ocupadas e as disposições a ocupá-las permite compreender que a juventude possa ser concomitantemente o tempo da revolta e o da adaptação. O tempo da revolta cada vez que se percebe a distância entre as posições efetivamente ocupadas após as classificações relativas aos novatos/pretendentes e as posições esperadas por eles (suas autoclassificações).

Essas distâncias entre as disposições e as posições permitem explicar diferentes formas de luta, individuais ou coletivas, que visam ao ajuste das disposições e das posições. Busca de posições ajustadas às disposições, por um lado: quer se trate dos conflitos de gerações em que os pretendentes tentam "queimar etapas" nas lutas pela sucessão, ou das diferentes formas, individuais e coletivas, de resistência à desclassificação, tornadas possíveis pela situação anteriormente descrita de ausência de gravidade econômica (relativa e provisória), ou ainda da invenção de novas posições ou da redefinição de antigas posições mais adaptadas às suas disposições.

A juventude aparece então como o tempo necessário para encontrar o seu lugar. Como não é possível aceder a posições ajustadas às disposições, o jeito é ajustar as disposições às posições acessíveis, interiorizar a ordem das sucessões, a nova equivalência entre os títulos e os cargos. Trata-se então de "refrear as pretensões", de levar a sério, enfim, de envelhecer. E a juventude aparece então como "o momento de aceitar", o tempo necessário para enterrar as ilusões. Quando, ao inverso, as classificações recebidas pelos jovens correspondem à sua autoavaliação e suas disposições estão ajustadas a suas posições, a reprodução das estruturas sociais se efetua sem tropeços. Por isso, é compreensível que a juventude possa ser sucessivamente revoltada ou apática, dissidente ou conformista, revolucionária ou conservadora.

\section{A Idade da Cristalização dos Habitus}

A transmissão entre gerações familiares dos diferentes tipos de capital - econômico, cultural, social, simbólico -, a conversão do capital cultu- 
ral herdado em capital escolar, o investimento dos capitais acumulados no mercado de trabalho e no mercado matrimonial supõem a interiorização das disposições que permitem apropriar-se dessas heranças, converter o capital cultural herdado em capital escolar, o "sentido dos limites" e o "sentido do investimento" que permitem orientar-se no mercado do trabalho como no mercado matrimonial. A interiorização dessas disposições características de um "habitus de classe" ocorre paralelamente à acumulação primitiva das diferentes espécies de capital. A dialética que se estabelece entre as disposições, o capital já adquirido e as posições às quais ele permite pretender ("o futuro de classe") acomoda uma parte de indeterminação relativa - objetiva e subjetiva que se reduz ao longo do tempo e que é resolvida pelo acesso a uma situação profissional e matrimonial: o encerramento da sequência "juventude" que impõe o ajuste das disposições à posição efetiva, que leva os agentes a se "tornarem aquilo que são" e a "se contentarem com o que têm", aparece então como um momento de estabilização das disposições, de cristalização dos habitus.

Ao término desta tentativa de esclarecimento, gostaria de ter mostrado a que se referem - ao menos implicitamente - os diversos usos correntes e eruditos da noção de "juventude". Tratava-se de destacar os motivos que levam a delimitar "classes de idade" pelo menos "no papel". Mas ocorre com as "classes de idade" o mesmo que com as "classes sociais" 2 . Delimitá-las "no papel" é simplesmente indicar agrupamentos possíveis, senão prováveis, e também mostrar o que as práticas e as disposições desta ou daquela categoria de agentes podem dever ao seu pertencimento a uma geração ou a uma mesma posição no "ciclo de vida". Mas é bem grande a diferença entre a existência de "grupos no papel" e a de grupos mobilizados, da "geração em si" e da "geração para si", se transpusermos a terminologia de Lukács para o caso das gerações. A existência de "gerações para si" não está excluída. Supõe admitir a existência de grupos sociais desigualmente sólidos e duráveis, atravessados por múltiplas oposições (entre classes sociais, entre sexos etc.). Ela é tanto mais provável quanto mais fraca for sua extensão social (reduzida a uma classe social ou a um campo) e supõe um trabalho de mobilização na base acumulada do "efeito de idade" e do "efeito de geração" em uma conjuntura favorável.

(Recebido para publicação em abril de 2012)

(Reapresentado em setembro de 2012) (Aprovado para publicação em janeiro de 2013) 


\section{NOTAS}

1. A esse respeito, cf. Mauger (1989).

2. Sobre a distinção entre "classes no papel" e "classes mobilizadas", cf. Bourdieu (1984:3-12).

\section{REFERÊNCIAS BIBLIOGRÁFICAS}

BOURDIEU, Pierre. (1978), Entrevista publicada em Les Jeunes et le Premier Emploi. Paris, Association des Âges, pp. 520-530, reeditada em P. Bourdieu, Questions de Sociologie. Paris, Les Éditions de Minuit, 1980, pp. 143-154.

. (1979), “Les Trois États du Capital Culturel”. Actes de la Recherche en Sciences Sociales, no 30, pp. 3-6.

. (1984), "Espace Social et Genèse des Classes". Actes de la Recherche en Sciences Sociales, nos. 52-53, pp. 3-12.

. (1989), La Noblesse d'État. Grandes Écoles et Esprit de Corps, Paris, Éditions de Minuit (4a parte, cap. 1, pp. 373-427).

(1992), Les Règles de l'Art. Genèse et Structure du Champ Littéraire. Paris, Éditions du Seuil.

(1996), "Qu'est-ce que Faire Parler un Auteur? À Propos de Michel Foucault”. Sociétés et Représentations, "Michel Foucault. Surveiller et punir: la prison vingt ans après", no 3, novembro, pp. 13-18.

CHAMBOREDON, Jean-Claude. (1985), “Adolescence et Post-Adolescence: la 'Juvénisation'”, in A-M. Alléon, O. Morvan e S. Lebovici (orgs.), Adolescence Terminée, Adolescence Interminable. Paris, PUF, pp. 13-28.

KESSLER, Denis e MASSON, André (eds.). (1985), Cycles de Vie et Générations. Paris, Éditions Economica, pp. 285-321.

MANNHEIM, Karl. (2011), Le Problème des Générations. Paris, Armand Colin (trad. do alemão por Gérard Mauger e Urainia Perivolaropoulou).

MAUGER, Gérard. (1989), “Les Héritages. Éléments pour une Analyse des Rapports entre Générations Familiales", in M. Freyssenet e S. Magri (orgs.), Les Rapports Sociaux et leurs Enjeux, vol. 1, CSU, pp. 101-124.

(1995), “Jeunesse: 1'Âge des Classements. Essai de Définition Sociologique d'un Âge de la Vie". Recherches et Prévisions, no 40, pp. 19-36.

. (2009), "Générations et Rapports de Générations", in A. Quéniart e R. Hurtubise (orgs.), L'Intergénérationnel. Regards Pluridisciplinaires, Rennes, Presse de L'EHSP, pp. 17-36. 


\section{Gérard Mauger}

. (2010a), “Crise de Reproduction et Désouvriérisation des Classes Populaires en France", in J. Hamel et alii (orgs.), La Jeunesse n'est plus ce qu'elle Était. Rennes, Presses Universitaires de Rennes, pp. 187-196.

. (2010b), “Jeunesse: Essai de Construction d'Objet". Agora Débats/Jeunesse, no 56, pp. 9-24.

PERCHERON, Annick e RÉMOND, René (eds.). (1991), Âge et Politique. Paris, Éditions Economica.

WITTGENSTEIN, Ludwig. (1990) [1931], Remarques Mêlées (fragments de 1914 à 1951), Edição bilíngue, Mauvezin, Trans-Europe Express. 


\begin{abstract}
Youth: Ages of Life and Generations

This article begins showing that the three distinct, albeit related notions of "ages of life", "family generations", and "social generations" are all integral to the concept of "mode of reproduction". Next, it shows that "youth", defined as a sequence within biographical trajectories characterized by the double-sided accession to a stable position in the labor market and matrimonial market, can be simultaneously described as a period of "primitive accumulation", "weightlessness" and "status inconsistencies", "social indetermination", "classification" and "the crystallization of habitus".
\end{abstract}

Key words: youth; mode of reproduction; generations

\title{
RÉSUMÉ
}

Jeunesse: Âges de la Vie et Générations

On montrera d'abord que les trois notions distinctes mais liées d' "âges de la vie", de "générations familiales" et de "générations sociales" sont solidaires du concept de "mode de reproduction". On montrera ensuite que "la jeunesse", définie comme la séquence de trajectoire biographique caractérisée par le double processus d'accès à une position stabilisée sur le marché du travail et sur le marché matrimonial, peut être décrite à la fois comme une période d'"accumulation primitive", d' "apesanteur" et d' "incohérences statutaires", d'"indétermination sociale", de "classements" et de "cristallisation des habitus".

Mots-clés: jeunesse; mode de reproduction; générations 